\title{
TEOLOGÍA Y NEUROCIENCIAS. UNA ARTICULACIÓN PARA OTRA COMPRENSIÓN DE LA ESPECIFICIDAD INTERNA DE LA TEOLOGÍA **
}

Fecha de recepción: 3 de agosto de 2018

Fecha de aceptación y versión final: 31 de octubre de 2018

RESUMEN: El encuentro entre teología y neurociencias exige una articulación mediada por conceptos filosóficos y hermenéuticos. Pero no basta con establecer puentes reflexivos entre lenguajes y campos epistémicos. De cara a la teología, es necesario generar una comprensión alternativa que incida en la formulación de su especificidad interna. Aparecen claves interpretativas fundamentales como carne viviente, sensibilidad, relacionalidad, ser proyecto, organismo viviente. Ellas permiten la estructuración del discurso que se pretende. Lo específico de la teología queda formulado a partir del establecimiento de una racionalidad epistemológica y de una sola fuente primera y constitutiva de la teología (distinta a la escritura, tradición y magisterio, que no se reconocen como fuentes sino como medios de transmisión).

PALABRAS CLAVE: articulación neurociencias y teología; carne; sensibilidad; organismo viviente; especificidad interna de la teología; kénosis.

"Profesor e investigador en la Unidad de Humanidades de la Universidad Santo Tomás, Colombia: dominevico21@yahoo.com; ORCID: https://orcid.org/0000-0001-5022-1889

*El presente artículo es producto de una investigación doctoral. Nace del texto compuesto para la defensa de tesis doctoral (13 de septiembre de 2017); tesis titulada: "La carne vulnerable como fuente primera y constitutiva de la teología. Articulación del testimonio teológico de la carne con una visión neurocientífica evolutiva", (doctorado en teología, Pontificia Universidad Javeriana, Bogotá, 2017). 


\section{Theology and Neurosciences. An Articulation to Another Comprehension of the Internal Specificity of Theology}

ABSTRACT: The dialogue between theology and neurosciences requires an articulation mediated by philosophical and hermeneutical concepts. But it is not enough to establish reflexive bridges between languages and epistemic fields. Thinking about theology, it is necessary to generate an alternative comprehension that affects the formulation of its internal specificity. Fundamental interpretive keys appear as living flesh, sensitivity, relationality, being a project, a living organism. They allow to structure the discourse of the current paper. The specificity of theology is formulated from the establishment of an epistemological rationality and from a single source and constituent of theology (other than Scripture, Tradition and Magisterium, which are not recognized as sources but as means of transmission).

KEY WORDS: articulation between neurosciences and theology; flesh; sensitivity; living organism; internal specificity of theology; kenosis.

\section{ESTRUCTURA DEL ARTÍCULO Y PREGUNTA}

El presente artículo está dividido en ocho partes (desarrolladas en el segundo punto). Con esta división se busca dar razón del contexto de la hipótesis de investigación, de los fundamentos y argumentos, de los resultados, novedades, impactos y conclusiones. La pregunta problema que dirige este texto es: ¿cómo articular la teología con una visión neurocientífica, sin descuidar que dicho encuentro, en cuanto posibilita una nueva comprensión, afecta la especificidad interna de la teología?

\section{ARTICULACIÓN PARA OTRA COMPRENSIÓN DE LA ESPECIFICIDAD INTERNA DE LA TEOLOGÍA}

\subsection{INTRODUCCIÓN}

La teología requiere mediaciones (lingüísticas, analíticas, sociales, políticas, entre otras), para expresar su intellectus y para enriquecerse en su quehacer. Pero también busca crear encuentros en los que, más que recurrir a instrumentalizaciones de otras disciplinas y ciencias, le permitan volverse a comprender desde su especificidad. La razón de ello es que la teología es dinámica. No puede estar acabada sobre sí misma. 
En este horizonte, es relevante el encuentro que realiza, por ejemplo, con las ciencias de la vida o estrictamente con las neurociencias. En las nuevas explicaciones sobre el sistema nervioso y el cosmos, en las antropologías de las neurociencias, en suma, en esas visiones científicas de mundo que ofrece dicho campo, la teología puede estructurarse de nuevo en una clave pertinente a su ser. No solo entra en contacto con otras racionalidades epistémicas y otros campos de lenguaje; sino que se deja hacer a partir de ellos. Pero para lograr este estado de cosas, es importante acotar las maneras del encuentro. No se trata de una traducción de metáforas del campo científico al lenguaje de la teología; tampoco de sintetizarlas en una sola visión ni de hacer de una el corrector ontológico de la otra; menos aún, de contraponerlas como lenguajes totalmente ajenos entre sí. Lo que salta a la vista es el asunto del cómo proceder y desde qué claves de comprensión, y que esto permita incidir en lo propio o específico de la teología (que es el asunto de interés en este artículo).

\subsection{El CONTEXTO DE LA HIPÓTESIS}

Quizá cada vez que alguien lee en el Evangelio de Juan que Jesús es la luz, no deja de pensar en la luz que conocen sus sentidos, y, posiblemente, informado por los avances de la física contemporánea, se le ocurra reducir la divinidad a la luz cósmica. Otro tanto podría ocurrir con los actuales descubrimientos sobre el sistema nervioso y la fascinación que produce el conectoma neuronal. Pero ¿qué decir de estas transposiciones de lenguajes de un campo a otro? ¿Acaso, la teología se estructura a partir de estos préstamos metafóricos directos? Frente a estos asuntos, algunos teólogos inspirados en Jean Ladrière han insistido en la necesidad de una articulación entre el lenguaje teológico y el de la ciencia o sencillamente entre el encuentro de lenguajes. Han notado que el intercambio semántico requiere una mediación reflexiva y conceptual para evitar discursos transpuestos de manera directa ${ }^{1}$. Así, se tiene cierto cuidado para

1 El tema de articulación entre ciencia y religión (ciencia y teología), es mantenido como propuesta en la facultad de teología de la Universidad Católica de Lovaina, bajo el influjo y herencia intelectual de Jean Ladrière. Cabe referir algunos ejemplos de la producción bibliográfica: a) la propuesta articuladora de lenguajes: Jean Ladrière, L'articulation de sens I. Discours scientifique et parole de la foi (Paris: Cerf, 1970); L'articulation de sens II. Les langages de la foi (Paris: Cerf, 1984); L'articulation de sens III. Sens et vérité en théologie (Paris: Cerf, 2004); "Science et théologie", Revue 
no lanzar términos al aire que pudieran ser equívocos o ambiguos: por ejemplo, decir sin más ni más, «la partícula de Dios», «el átomo divino», «los fotones de Dios» o «la neurona de Dios».

La exigencia de una reflexión conceptual, y los aportes precedentes sobre las investigaciones entre ciencia y teología, condujeron el presente artículo a preguntarse por las características del encuentro en el caso específico de las neurociencias y la teología. En la indagación del estado de la cuestión se encontraron, principalmente, dos cosas: a) que la reflexión sobre dicho encuentro es reciente, ya que las neurociencias tienen un poco más de cincuenta años ${ }^{2}$ y, b) que, entre los esfuerzos por comenzar a relacionar teología y neurociencia, hay trabajos que las vinculan directamente (sin mediación filosófica) como es el caso de la llamada «neuroteología» ${ }^{3}$ o que hacen una yuxtaposición de antropologías (de la Biblia con la antropología de las neurociencias), como es el caso de A. Ganoczy ${ }^{4}$, y, el encuentro se queda o en un intercambio directo o en una yuxtaposición de lenguajes. El inconveniente de esto es que proceder por intercambio directo o por yuxtaposición es transgredir los campos de lenguaje de la ciencia y de la teología y no respetar su especificidad ${ }^{5}$.

Théologique de Louvain 34 (2003): 3-26 ; b) trabajos que buscaron la articulación: Dominique Lambert, Sciences et théologie. Les figures d'un dialogue (Namur: Lessius, 1999); "Une articulation des sciences et de la théologie est-elle légitime?", Nouvelle revue théologique 119 (1997): 520-540; Benoît Bourgine, Bernard Feltz, Pierre-Joseph Laurent, y Ph van den Bosch de Aguilar, dirs., Darwinismes et spécificité de l'humain (Louvain-la-Neuve: Editions Academia, 2012); Luis Orlando Jiménez-Rodríguez, The articulation between natural sciences and systematic theology. A philosophical mediation based on the contributions of Jean Ladrière and Xavier Zubiri (Leuven-Paris-Bristol: Ed. Ephemerides theologicae lovanienses, 2015); "It is reasonable to upload a non-reductive Christian monism? Theology confronted with the mind-brain and body-soul problem”, Pensamiento 71, n. ${ }^{\circ} 269$ (2015): 1323-1345.

2 Herbert H. Jasper, et. al., "Neuroscience", en History of the American physiological society. The first century, eds. John R. Brobeck, Orr E. Reynolds, y Toby A. Appel (New York: Library of Congress, 1987), 427-434, 429.

3 Para el inicio del concepto de neuroteología: Luis E. Echarte, "Proyección y límites de la neuroteología en el pensamiento de Aldous Huxley. La interdisciplinariedad a prueba en estudios existenciales", Persona y bioética 13, n. ${ }^{\circ}$ 1. (2009): 42-58, 4445; un recuento de la neuroteología y neuroreligión: Ramón María Nogués, Dioses, creencias y neuronas. Una aproximación científica a la religión (Barcelona: Fragmenta editorial, 2011), 148-150.

4 Para una teología donde se yuxtapone antropología bíblica con neurociencias: Alexandre Ganoczy, Cristianisme et neurosciences. Pour une théologie de l'animal humain (Paris: Odile Jacob, 2008).

5 Luis Orlando Jiménez-Rodríguez, The articulation between natural sciences and systematic theology, 27-35. 
Se hacía necesario optar por otra forma de encuentro que evitara las transposiciones directas de los distintos campos semánticos y las yuxtaposiciones. Se halló pertinente la propuesta de J. Ladrière acerca de una articulación de lenguajes y de una mediación filosófica entre ciencias y teología, pues articular implica respetar los campos lingüísticos, epistémicos y metódicos de cada saber. Además, consiste en permitir el cruce semántico (transgresión semántica) siempre y cuando exista una mediación filosófica, hermenéutica y conceptual entre los dos lenguajes, para así evitar estas transposiciones directas ${ }^{6}$. Al respecto cabe recordar que algunos autores hablan de una independencia de campos y métodos entre ciencia y teología (esto fomenta la corrección mutua); otros, de un conflicto entre visiones (esto fomenta cientificismos y teologicismos como el creacionismo y la lectura literalista de la Biblia); y, otros, buscan un concordismo (fomentan la creencia en una religión natural y la interpretación bíblica acrítica) ${ }^{7}$. El trabajo de la articulación se hizo fundamental ya que solucionaba varios problemas de tipo epistemológico y metódico al momento de realizar el encuentro entre neurociencias y teología: evitaba la transposición directa de metáforas, la yuxtaposición de lenguajes y visiones del mundo, el correccionismo entre disciplinas, los reduccionismos cientificistas o teologicistas y el concordismo bíblico con los hallazgos de la ciencia ${ }^{8}$.

A partir de allí, la presente investigación se hizo pertinente de muchas maneras. Sería necesario proponer las condiciones de posibilidad de este encuentro, reflexionar el encuentro mismo (esto incluiría detectar algunas categorías y conceptos que permitieran la articulación) y

6 Ibid., 34-35.

7 Acerca de las diferentes posturas sobre el diálogo ciencia-religión y ciencia-teología: John Polkinghorne, Ciencia y teología. Una introducción (Santander: Sal Terrae, 2000), 38-40; Agustín Udías Vallina, Conflicto y diálogo entre ciencia y religión (Santander: Sal Terrae, 1993), 23-38; Raimon Panikkar, Ontonomía de la ciencia. Sobre el sentido de la ciencia y sus relaciones con la filosofía (Madrid: Gredos, 1961); para tratar acerca del creacionismo y al literalismo bíblico: Emilio Cáceres Vázquez, Creacionismo y diseño inteligente frente a evolución. Un debate inexistente (Madrid: Hélice, 2011), 20-28.

8 Acerca de la necesidad de una articulación: Jean Ladrière, L'articulation de sens II, 289-296; Dominique Lambert, "Une articulation des sciences et de la théologie", 526; Luis Orlando Jiménez-Rodríguez, The articulation between natural sciences and systematic theology, 369-391. Acerca de una crítica a los encuentros entre antropologías: Luis Orlando Jiménez-Rodríguez, "It is reasonable to upload a non-reductive christian monism?". 
comprender lo que significa este ejercicio con relación al rostro de la teología. Esto último situaba la búsqueda en la pregunta por la manera en que una articulación entre teología y neurociencia desafiaba el intellectus de lo específico de la teología. O sea, la forma en que las categorías del encuentro se convertían en una clave de estructuración de la especificidad interna de la teología. Al fin y al cabo, el discurso sobre lo específico de la teología no podía quedar ajeno al aporte del lenguaje de la ciencia. Hacer lo contrario significaría tomar una actitud defensiva y reduccionista frente a cualquier repercusión encontrada.

Pero hasta aquí parecía que el contexto partía de un problema solamente especulativo. Sin embargo, esta idea quedó superada por dos razones: a) porque no se podía seguir manteniendo el discurso de que lo teórico-especulativo es contrario a la acción, o viceversa; b) porque se intuía que lo relativo al sistema nervioso y al asunto de Dios se teje en las experiencias de la vida cotidiana, no solamente cuando alguien testimonia que siente a Dios, que escucha la Palabra de Dios, que ve a Dios, que sueña con Dios o que actúa según la voluntad y el sentir de Dios, y demás. Lo llamativo de esto y que definió el enfoque fue ver que estas experiencias emergían de un ser humano concreto, un viviente, un organismo vivo que en su existencia cotidiana es capaz de realizarse en dichas vivencias. Es así como la investigación adquiría su consistencia: lo cotidiano del organismo vivo llamado humano. De esta manera la pregunta de investigación no estaría desconectada de la vida diaria: ¿cómo articular el encuentro entre teología y neurociencia sin perder de vista al ser humano concreto, en su "praxis del vivir» o en su existencia cotidiana, y sin olvidar que esta articulación recaería en una reflexión sobre la especificidad interna de la teología?

\subsection{LOS FUNDAMENTOS}

Fue así como se llegó a la hipótesis que atravesó toda la investigación: la vida humana es experiencia; pero no es una experiencia abstracta, sino que se constituye a partir del vivir mismo. Es también existencia, pero dado que existir es un verbo que exige un rostro concreto, esta existencia no es un concepto abstraído del ámbito del vivir mismo ni del organismo viviente que se realiza en aquello que se suele denominar como existencia, sino una situación propia del «ser ahí»; una situación propia 
del organismo viviente y su entorno ${ }^{9}$. La hipótesis asumió lo anterior, es decir la perspectiva concreta del ser y del ser organismo viviente, como clave metódica para el encuentro y la articulación entre teología y neurociencia. Al fin de cuentas, no es viable separar el vivir concreto de un organismo vivo de su existencia, ni de su praxis de vivir ${ }^{10}$.

Por otra parte, desde el punto de vista de la antropología bíblica, se encontró que la manera de asumir este ser concreto es mediante la palabra, acontecimiento y testimonio referido como bāśâr (carne, ser viviente y relacional). Bāśâr, en el A. T., es carne, relacionalidad, experiencia, existir, sensibilidad y vivencia ${ }^{11}$. En el testimonio del N. T., especialmente en el prólogo de Juan $(1,14)$, es abreviación y plenitud de la divinidad en un ser viviente llamado Jesús; y, en Pablo (1Cor 1, 17-18) la carne es la sabiduría de Dios y ello como acontecimiento desconcertante ${ }^{12}$. En todo

9 Sobre la situación del ser ahí y la teología: Martin Heidegger, "Fenomenología y teología”, en Hitos, versión de Helena Cortés y Arturo Leyte (Madrid: Alianza Editorial, 2000), 45-78; acerca del Dasein en general: Martin Heidegger, Identidad y diferencia

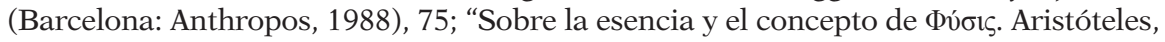
Física, B, 1", en Hitos, versión de Helena Cortés y Arturo Leyte (Madrid: Alianza Editorial, 2000), 129-134; De la esencia de la verdad. Sobre la parábola de la caverna y el Teeteto de Platón (Madrid: Herder, 2007), 71-75; acerca de la carne como ser ahí: Michel Henri, Encarnación. Una filosofía de la carne (Salamanca: Sígueme, 2001), 17-19.

10 Acerca de la praxis del vivir: Humberto Maturana, La objetividad, un argumento para obligar (Santiago de Chile: Dolmen, 1997), 19-20; Óscar Castro García, "La biosemiótica y la biología cognitiva en organismos sin sistema nervioso", Ludus vitalis XIX, n. ${ }^{\circ} 36$ (2011): 47-84.

11 E. Schweizer, “B. Carne nell' A. T.”, en Grande Lessico del Nouvo Testamento $X I$, dir. Gerhard Kittel; ed. Gerhard Friedrich; trad. al italiano por F. Montagnini,

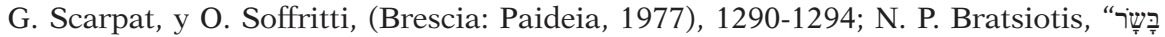
bāsāar", en Theological dictionary of the Old Testament II, eds. G. Johannes Botterweck, Heinz-Josef Fabry, y Helmer Ringgren; trad. John T. Willis (Michigan: Eerdmans, 1983), 317-332; Luis Alonso Schökel, “ "שฺָָ̣ bāśār, carne”, en Diccionario bíblico hebreo-español, eds. Víctor Morla y Vicente Collado (Madrid: Trotta, 1994), 139-140.

12 Algunos textos sobre la carne y el prólogo de Juan: Hans Urs von Balthasar, Gloria. Una estética teológica, 7 (Madrid: Encuentro. 1989), 32-34; Klaus Wengst, "Il prologo (1, 1-18)", en Il Vangelo di Giovanni (Brescia: Queriniana, 2005), 31- 77; Luis Guillermo Sarasa Gallego, La filiación de los creyentes en el Evangelio de Juan (Bogotá: Edición Facultad de Teología, Pontificia Universidad Javeriana, 2010), 61-69; "El prólogo de Juan, un principio y fundamento", Cuestiones teológicas 39, n. 91 (enero-junio, 2012): 99-117. Algunos textos sobre Filipenses y Corintios: Senén Vidal, "Filipenses", en Las cartas auténticas de Pablo, (Bilbao: Mensajero, 2012), 529-568; El proyecto mesiánico de Pablo (Salamanca: Sígueme, 2005), 9-26; Las cartas originales de Pablo (Madrid: Trotta, 1996), 158-257. 
caso, bāśär expresa el carácter concreto del ser ahí: lo concreto del ser ahí se manifestó como la carne ${ }^{13}$.

Además, la indagación bíblica podía hallar consonancias en las nuevas visiones antropológicas de la ciencia. La antropología de las neurociencias permitía concebir a un viviente que se realiza por la experiencia, la relacionalidad y por la sensibilidad. Hablar de sistema nervioso y, en él, del cerebro indica que se trata de una realidad que supera el solipsismo; que no está encerrada en sí misma, sino que permanece y se constituye a partir de la relación con el entorno y, por la sensibilidad, está siempre haciendo del entorno una experiencia vital. El cerebro emerge en la necesidad de movimiento (R. Llinás); consiste en una plasticidad creativa del conectoma (S. Seung); se está transformando constantemente generando nuevas cartografías neuronales (G. Edelman); y realiza al organismo viviente desde un equilibrio homeostático (A. Damásio), autocreativo (H. Maturana y F. Varela) ${ }^{14}$. Había una pista: la carne como ser ahí concreto; pero aún hacía falta el trabajo de articulación de lenguajes.

13 Sobre una ontología de la carne: Henri, 17-19; La carne en la tradición cristiana de San Ireneo: Sancti Irenaei Episcopi Lugdunensis, Libros quienque adversus haereses. Textu gaeco in locis nonnullis locupletato, versione latina cum codicibus claromontano ac arundeliano denuto collata. Tom. II. Collegii, W. Wigan Harvey, STB. (Cantabrigiae: Typis Academicis, 1857), 349-353; Antonio Orbe, Teología de san Ireneo IV. Traducción y comentario del libro IV del Adversus Haereses (Madrid: BAC maior, 1996), 274-276; San Ireneo de Lyon, Demostración de la predicación apostólica. Fuentes patrísticas 2, trad. Eugenio Romero Pose (Madrid: Ciudad Nueva, 1992), Demostración 5; Sergio Zañartu, "La salvación de la carne según Ireneo en Adv. Haer. V, 1-14. Breve presentación de conjunto. 'Fructus autem operis spiritus est carnalis salus' (V, 12, 4, 77s)”, Teología y vida 54 (2013): 43-78; Emmanuel Falque, Dios, la carne y el otro. De Ireneo a Duns Scoto: reflexiones fenomenológicas (Bogotá: Siglo del Hombre editores, 2012), 243 y 251; Bernard Sesboüé, Tout récapituler dans le Christ. Christologie et sotériologie d'Irénée de Lyon (Paris: Desclée, 2000), 66.

14 Sobre la sensibilidad del organismo viviente: Xavier Zubiri, Sobre el hombre (Madrid: Alianza Editorial, 1986), 457-458; acerca de la sensibilidad en que consiste el sistema nervioso: "Cómo se conectan las neuronas", Redes para la ciencia. Emisión 160 del 16 de junio de 2013. Temporada 17, Consultado el 03 de marzo de 2017, http:// www.redesparalaciencia.com/wp-content/uploads/2013/06/entrev1601.pdf; Rodolfo R. Llinás, El cerebro y el mito del yo. El papel de las neuronas en el pensamiento y el comportamiento humanos (Bogotá: Ed. Normal, 2003) 70; Antonio Damásio, El error de Descartes. La razón de las emociones (Santiago de Chile: Andrés Bello, 1996), 18; Sentir lo que ocurre. Cuerpo y emoción en la fábrica de la conciencia (Santiago, Chile: Salesianos S.A., 2000), 305-322; Y el cerebro creó al hombre. ¿Cómo pudo el cerebro generar emociones, sentimientos, ideas y el yo? (Barcelona: Destino, 2010), 426-430; Gerald M. Edelman, Biologie de la conscience (Paris: Éd. Odile Jacob, 1994); Francisco Varela, El 


\subsection{LA ARTICULACIÓN ${ }^{15}$}

En primer lugar, la carne es testimoniada en el Antiguo Testamento como ámbito propicio para la amistad con Yahveh. La condición de posibilidad de esta amistad es que la carne significa relacionalidad, sensibilidad y experiencia. De allí se desprende que los documentos que hablan de carne y de Yahveh (principalmente los que no hacen parte del acervo sacerdotal ni deuteronomista), siempre propongan una relación de iguales, de cercanía y conocimiento mutuo ${ }^{16}$. Una ojeada sobre las tradiciones y los documentos veterotestamentarios que tratan al respecto permite reconocer un testimonio positivo del vínculo entre Yahveh y

fenómeno de la vida (Santiago de Chile: Dolmen, 2002), 239-368. Santiago Ramón y Cajal, Histología del sistema nervioso del hombre y de los vertebrados. Tomo I (Madrid: Ministerio de Sanidad y consumo, 2007), 620-622. Norman Geschwind, "Especializaciones del cerebro humano", Investigación y ciencia, El lenguaje humano 5 (1996): 8-19.

15 Algunos acercamientos precedentes entre religión y neurociencias, teología y neurociencias (aunque no se trata de articulaciones ni tienen por temática el asunto fundamental y específico de la teología), pueden ser: John F. Haught, God after Darwin. A theology of evolution (Philadelphia: Westview Press, 2008); Niels Henrik Gregersen, "Emergency and Complexity", en The Oxford Handbook of Religion and Science, ed. Philip Clayton (Oxford: Oxford University Press, 2008), 767-783; Adolphe Gesché, "L'invention chrétienne du corps", en Le corps chemin de Dieu, eds. Aldolphe Gesché y Paul Scolas (Paris: Les éditions du Cerf, 2005), 33-75; Carol Rausch Albright, "James B. Ashbrook and his holistic world: Toward a 'unified field theory' of mind, brain, self, world, and God", Zygon 45, n. 2 (June 2010): 479-489; Lluís Oviedo y Álvaro Garre, “The interaction between religion and science in Catholic southern Europe (Italy, Spain, Portugal)", Zygon 50, n. 1 (March 2015): 172-193; Charlene P. E. Burns, "Christianity and the cognitive sciences", en The Routledge Companion to Religion and Science, eds. James W. Haag, Gregory R. Peterson, y Michael L. Spezio (New York: Routledge. 2014), 308-319; Kirk A. Bingaman, "Beyond Original Sin: A Paradigm Shift for the Age of Neuroscience", Pastoral Psychology 61, (2012): 411-422; Ron Cole-Turner, "Entheogens, mysticism, and neuroscience", Zygon 49, n. 3 (September 2014): 642-651; Leonard Hummel, "By its fruits? Mystical and visionary states of consciousness occasioned by entheogens", Zygon 49, n. ${ }^{\circ} 3$ (noviembre 2014): 685-695; Philip Clayton, Adventures in the Spirit. God, World, divine Action (Minneapolis MN: Fortress Press. 2008); Philip Clayton, y Arthur Peacocke, eds., In whom we live and move and have our being. Panentheistic Reflections on God's Presence in a Scientific World (Cambridge: Eerdmans, 2004).

16 Para una teología de las tradiciones de Israel, específicamente de Yahvéh: Gerhard von Rad, Teología del Antiguo Testamento I. Las tradiciones históricas de Israel, ed., Luis Alonso Schökel (Salamanca: Sígueme, 1993), 148; José Loza Vera, Raúl Duarte Castillo, Introducción al Pentateuco, Génesis. Biblioteca bíblica básica 3 (Estella: Verbo Divino, 2007), 67-68; Tesis doctoral: "la carne vulnerable como fuente primera y constitutiva de la teología", 80-93. 
la carne. Curiosamente, las condiciones están dadas por la carne misma en cuanto que ella es relacionalidad. Así, desde los escritos tribales sobre la vida de Moisés y de su suegro Jetró, el sacerdote de Madián, hasta las teologías tribales de la promesa a Abraham, Yahveh y la carne son amigos que se ocupan de la acogida, la hospitalidad y la causa de la persona vulnerable. Sin embargo, en los documentos de inspiración sacerdotal y deuteronómicos es donde la carne es tomada en sentido negativo, como pecaminosidad. En estas teologías, Dios permanece alejado, se hace cósmico y exige un comportamiento legal y cultual, pues encuentra que la carne se ha corrompido. La manera de resarcir esto será con sacrificios rituales. Valga decir que esto último ha representado un gran inconveniente a la hora de resaltar la antropología positiva de la carne en toda la Biblia. De todas maneras, este ejercicio sobre la Biblia permite reconocer que la carne es la fuente y ámbito del encuentro con Yahveh ${ }^{17}$.

A partir del horizonte formulado por el teólogo von Balthasar, en el Antiguo Testamento, la carne era concebida como instrumento y mediación de Dios para lograr un objetivo. Así, los profetas recibían la Palabra de Yahveh y la comunicaban. No se la atribuían a sí mismos, como si ellos fueran su fuente, sino que la testimoniaban como venida de Yahveh y dirigida al pueblo haciendo de ellos un instrumento de comunicación. En cambio, en el Nuevo Testamento, hay una carne, la de Jesús, que es testimoniada por sus seguidores como fuente de toda Palabra divina. Ya no es una carne que recibe la Palabra, sino una carne que es Palabra; la fuente de esta Palabra divina es la carne misma ${ }^{18}$. Como se ve en este modo de proponer el asunto, la carne ya no se instrumentaliza, sino

17 Para una teología del Antiguo Testamento donde se muestra al hombre como llamado a la amistad con Yahveh: José L. Sicre, Los profetas de Israel y su mensaje. Antología de textos (Madrid: Cristiandad, 1986), 20-21; Walter Eichrodt, Teología del Antiguo Testamento I (Madrid: Cristiandad, 1975), 125-126; Walter Brueggemann, Teología del Antiguo Testamento. Un juicio a Yahvé (Salamanca: Sígueme, 2007), 43; Hans De Wit, En la dispersión el texto es patria. Introducción a la hermenéutica clásica, moderna y postmoderna (San José Costa Rica: Universidad Bíblica Latinoamericana, 2002), 140-141; "Interlinear Bible", Bible Hub, 2004-2017, consultado 08 de diciembre de 2018, http://biblehub.com/interlinear/; para un tratado sobre la carne en el Antiguo Testamento: Wolfgang Beinert, Die Leib-Seele-Problematik in der Theologie

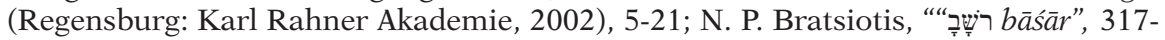

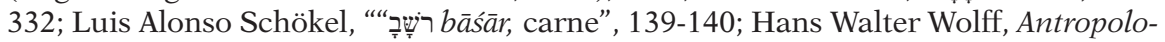
gía del Antiguo Testamento (Salamanca: Sígueme, 1975).

18 En cuanto a la palabra en la carne de los profetas como distinta a la palabra en el Nuevo Testamento: Hans Urs von Balthasar, Gloria, 32; Falque, 254. 
que recupera el horizonte primitivo del culto tribal a Yahveh. En el testimonio de los seguidores de Jesús, la amistad que hay entre la carne y Yahveh es expresada lingüísticamente con el término Abbá, como estricta cercanía, como no dualidad. Valga anotar aquí que esta comprensión de la carne rompe el modelo teísta de Dios, pues ya no se trata de un ser alejado e inasible que demanda satisfacción por el pecado, sino un ser dado a la experiencia y a la sensibilidad. Cabe acotar que, cuando san Pablo habla de la carne en sentido negativo, se puede entender que es una carne que no ha dado el paso a la novedad que representa la sensibilidad de Jesús: no haber dado el paso al «hombre nuevo» ${ }^{19}$.

Una vez detectado el testimonio teológico de la carne en este horizonte bíblico, se dio el paso a la propuesta de la visión neurocientífica. El interés no solo era movido por el reconocimiento de la humanidad de Jesús y de que algo tuvo que ocurrir en su sistema nervioso (entiéndase sensibilidad e inteligencia) para ser testimoniado por sus seguidores como la carne fuente plena de la experiencia de Dios, sino también

19 Sobre el Antiguo Testamento como epistemología del Nuevo Testamento: Hans Urs von Balthasar, Gloria, 31; Teodramática I (Madrid: Encuentro, 1990), 35-38; Sobre la carne en Juan y en Pablo: Alfred Wikenhauser, "Prólogo 1, 1-18", en El Evangelio según san Juan (Barcelona: Herder, 1972), 61-88; Senén Vidal, "Filipenses", 529-568; Elsa Támez, "La carta de Pablo a los Filipenses desde la perspectiva de un prisionero político", Revista bíblica 3, n. ${ }^{\circ} 4$ (2012): 193-217; Thomas Söding, "Encarnación y pascua, la historia de Jesús tal como se refleja en el Evangelio de Juan", Selecciones de teología 42, n. ${ }^{\circ} 172$ (oct-dic 2004): 305-312; Raymond E. Brown, La comunidad del discípulo amado. Estudio de la eclesiología juánica (Salamanca: Sígueme, 2005); El evangelio según Juan I-XII (Madrid: Cristiandad, 1999), 11-44; Juan Mateos, y Juan Barreto, El evangelio de Juan. Análisis lingüístico y comentario exegético (Madrid: Cristiandad, 1992), 38; L. Alonso Schökel, Hermenéutica de la Palabra. I hermenéutica bíblica (Madrid: Cristiandad, 1986); Juan Luis Ruiz de la Peña, Imagen de Dios. Antropología teológica fundamental (Santander: Sal Terrae, 1988), 20; Maurice A. Robinson, William G. Pierpont, The New Testament in the Original Greek: Byzantine Textform (Chilton Book Publishing, 2005); Karl Rahner, Wilhem Thüsing, Cristología: estudio teológico y exegético (Madrid. Cristiandad, 1975), 31-32; Keener Craig S., "Commentary on 1 Corinthians", en 1-2 Corinthians (New York: Cambridge Press, 2005), 20-139; Giuseppe Barbaglio, Jesús de Nazaret y Pablo de Tarso. Confrontación histórica (Salamanca: Secretariado trinitario, 2009), 20; Acerca del hombre viejo y el hombre nuevo: Zañartu, 43-78; acerca de la teología de la cruz: Karl Rahner, Jürgen Moltmann, Christian Duquoc, Stanislas Breton, Abelardo Lobato, Ignace de La Potterie, Domenico Grasso, Walter Kasper, y Hans Küng, Teología de la Cruz (Salamanca: Sígueme, 1979); Jürgen Moltmann, El Dios crucificado. La cruz de Cristo como base y crítica de toda teología cristiana (Salamanca: Sígueme, 2010); "Resurrección y futuro de Jesucristo", en Teología de la esperanza (Salamanca: Sígueme, 1969), 181-298. 
que, en orden a la articulación, era preciso exponer el aporte de algunos avances de las neurociencias y la posible riqueza que podría aportar al testimonio teológico de la carne hallado en el horizonte bíblico.

Lo primero para anotar es que las neurociencias son una interdisciplinariedad en donde interactúan varias ciencias. La biología y la teoría de la evolución son fundamentales. Y esto representa una primera característica: los organismos vivos evolucionan; el sistema nervioso evoluciona y se explica desde los dinamismos de selección natural, aleatoriedad y mutación genética. Así pues, se trata de la vida en constante crecimiento que se desarrolla a partir del tejido de sus propias fuerzas, constituciones, bioquímicos y disposiciones genéticas de información ${ }^{20}$. Esa interacción sucede como una tensión a nivel de la estructura del organismo viviente, donde el tejido de operaciones se codetermina. Se trata de una tensión autogestionadora (cuando el organismo vivo recibe un influjo o estímulo del entorno, la respuesta depende de la estructura propia del organismo que es capaz de recrearse en relación con el entorno $)^{21}$. La evolución requiere incorporar el concepto de mutación aleatoria antes de querer explicar la vida desde el modelo teleológico o de finalidades. La vida se organiza y evoluciona a partir de la aleatoriedad. Lo que este concepto implica es que para que la vida evolucione es necesario un modelo que permita comprenderla en continua relación de fuerzas y elementos. Este es, además, el antecedente de lo que se ha venido a llamar la interacción entre organismo y el entorno.

De esta forma, entrar por las neurociencias implica asumir que la vida es relacionalidad. No hay un prediseño o diseño inteligente de las

20 Sobre las bases teóricas de la evolución: Charles Darwin, El origen de las especies por medio de la selección natural, Tomo I (Madrid-Buenos Aires: Espasa-Calpe, 1921), 50-104; para una historia de los estudios del cerebro: Carlos Blanco, Historia de la neurociencia. El conocimiento del cerebro y la mente desde una perspectiva interdisciplinar (Madrid: Siglo XXI, 2014), 22-23 y 27; sobre la evolución del cerebro: Llinás, 17-23 y 470; Damásio, El error de Descartes, 105-106; Y el cerebro creó al hombre, 97.

21 Acerca de la tensión autogestionadora (tensión autopoiética), entendida como codeterminación creativa de operaciones: Humberto Maturana, y Francisco J. Varela, Autopoiesis and Cognition. The realization of the living (London: Reidel Publishing Company, 1980), 112-123; la importancia de la praxis del vivir para la comprensión de la relación entre el sistema viviente y el entorno: Maturana, 17-18; Acerca de la tensegridad: Castro, 47-84; sobre la emergencia: Luis Orlando Jiménez Rodríguez, The articulation between natural sciences and systematic theology, 430-431; Philip Clayton, Adventures in the spirit, 63-116. 
especies y organismos, sino una relacionalidad que sucede en una tensión autoemergente (o sea, una autogestión aleatoria a partir de los constitutivos y de la estructura del organismo viviente en relación con el entorno vital). En el caso de organismos vivos con sistema nervioso, se entiende que tal sistema emerge desde la condición de posibilidad que representa la relacionalidad. Los asidiáceos son organismos sésiles, que viven como plantas; pero, cuando requieren hallar una nueva fuente de alimento desarrollan una red neuronal simple que les permite identificar una ruta hacia la comida y anticipar los posibles peligros en el camino. Al llegar a la comida, pierden el sistema nervioso y vuelven a ser sésiles o a vivir como plantas. Este dato implica que el sistema nervioso emerge como una respuesta a la necesidad de supervivencia y de bienestar y como incorporación del movimiento y de la anticipación de los peligros $^{22}$. Así pues, lo que se llamó aquí anteriormente relacionalidad asumió su rostro concreto en el caso de los organismos vivos con sistema nervioso: es una relacionalidad que interpreta el entorno a modo de movimiento-temporalidad para lograr la supervivencia y el bienestar.

Por su parte, los organismos vivos llamados humanos tienen esta misma base evolutiva en su sistema nervioso. Son relacionales y han hecho un camino evolutivo desde los sistemas sensibles musculares y de la piel hasta la conversión de dichos estímulos móviles en señales e información (aquí se ubica el significado de la emocionabilidad y la capacidad de decisión como maneras de representación del entorno y de respuesta al mismo). No hay separación entre motricidad-sensibilidad e inteligencia. Este asunto es de crucial importancia para entender la situación del cerebro humano. El cerebro humano no es un órgano como lo son el corazón o el hígado, como creyó la medicina hipocrática; tampoco es un conjunto de órganos funcionando entre sí, como creyó la frenología. Es más bien, según el aporte de Antonio Damasio y de Rodolfo Llinás, una red de redes; un supersistema de otros sistemas. Es más, si no es un órgano, el cerebro es más bien una red especializada de neuronas y mapas neuronales, que hacen parte de todo el entramado del sistema nervioso ${ }^{23}$.

La motricidad-sensibilidad e inteligencia en el sistema nervioso reúne lo que tradicionalmente se ha conocido como emociones, sentimientos,

22 Sobre la necesidad del movimiento (oscilaciones), en la evolución del sistema nervioso: Llinás, 20.

23 Antonio Damásio, El error de Descartes, 34. 
imágenes mentales, pensamientos y decisiones. En el caso del ser humano, se trata de una realidad relacional que está constantemente haciéndose a sí misma y haciendo el entorno. A modo de bucle ascendente. Este bucle es vivido como proyección al futuro (en ello consiste la capacidad de anticipación o de previsión). Las emociones son como un satélite en el espacio recibiendo toda clase de estímulos y los transduce en señales e información. Estas señales devienen en imágenes y mueven todo el organismo a reaccionar con una respuesta creativa. Esta respuesta creativa modifica el entorno, es decir, modifica la realidad. Este carácter relacional del ser humano lo hace un intérprete creativo, un ser que permanece en proyección.

Se observa aquí la riqueza del aporte de una visión neurocientífica del ser humano. La relacionalidad incluye la aleatoriedad, el movimiento y la creatividad. Aparece en alto relieve que esta organicidad viviente llamada humano emerge desde la autonomía del mundo, y se constituye en dicha autonomía. A partir de ello, toda su praxis, toda interpretación, toda existencia y cultura, además de la base biológica, sucede a partir de la autonomía de la materia en evolución. En esto hay que hilar fino porque no se sugiere un reduccionismo de todas las dimensiones humanas a la materia y su autonomía. Los conceptos que ayudan a evitar el reduccionismo son el de coemergencia y el de homeóstasis (coemegencia es la interacción de campos y de realidades con vistas a la complejidad; homeóstasis es el equilibrio que conserva la vida). Así pues, la cultura, la religión y los discursos de fe, no se reducen a lo biológico; pero sí emergen desde una base biológica. Emergen para lograr el equilibrio de la vida, la supervivencia y el bienestar del organismo y de la comunidad. En palabras de Antonio Damásio, la cultura y las realidades mentales ayudan aquel equilibrio y conservación de la vida: la homeóstasis. Nótese aquí que no se trata de una naturalización de un modo específico de cultura, ni de unos contenidos culturales. Se puede criticar diciendo que se avala un esencialismo cultural. Por el contrario, lo que se está diciendo es que las manifestaciones de la cultura y de la mente siguen bajo la característica de la creatividad de la vida ${ }^{24}$.

${ }^{24}$ La cultura en homeóstasis: Antonio Damásio, El error de Descartes, 34, 104105; Y el cerebro creó al hombre, 70. El gestor de la teoría de la evolución no estaría de acuerdo con una selección social en el caso del ser humano; vería las realidades sociales y culturales como coextensión de lo humano y a favor de los humanos: Charles Darwin, The descent of man, and selection in relation to sex (Princeton: 
Ahora bien, se hizo notar que el encuentro entre teología y la visión neurocientífica del ser humano exige un recurso que permita reconocer que, en ambos casos, se trata de distintos campos de lenguaje, diferentes epistemologías y métodos. También que, sin descuidar lo anterior, suscitara la posibilidad de un puente. Se trata de transitar de un campo metafórico a otro (diversos lenguajes), y de distintas visiones de mundo y de ser humano. Por ello fue importante considerar una manera que permitiera el respeto por cada campo y visión, sin perder de vista la necesidad del encuentro. La manera de proceder fue la articulación. Ella sirve de engranaje y mediación; además, permite la coexistencia de los dos campos de lenguaje en su epistemología y método, pero dando el paso al diálogo y a la transgresión metafórica (no una transposición, sino un caminar de la metáfora desde un campo hacia otro atravesando la mediación conceptual de la filosofía). No es suficiente con saber que en ambos campos (teología y neurociencias) hay lenguajes similares, sino que es crucial acudir al recurso de la mediación filosófica para proponer conceptualizaciones que fueran capaces de responder y asimilar lo fundamental de cada campo lingüístico. Es decir, que la mediación filosófica ayuda a la articulación en cuanto que genera conceptos que operan como una clase de conjuntos más amplia que los conceptos y metáforas de cada campo. Los asume, pero sin hacer de ellos un traduccionismo de metáforas directas; los asume dentro de una mayor capacidad conceptual.

\subsection{Estrategias para La ARTiculación}

Las estrategias consistieron en hallar términos y conceptos que permitan la articulación. ¿Cuál es la categoría o mapas de categorías, fundamentales en ambos casos, que han venido apareciendo hasta este momento del discurso? Los conceptos comunes en ambos casos son la relacionalidad, la sensibilidad y experiencia. Las categorías distintivas en el testimonio teológico de la carne son: la amistad cotidiana con Dios y la novedad de la carne de Jesús; y, en el caso de la visión neurocientífica, son: la autonomía de la materia en evolución y la sensibilidad que es

Princeton University Press. 1981), 36-37; Patrick Tort, "Ce qui a changé (dans) les études darwiniennes”, en Darwin dans la bataille des idées, dirs., Sophie Geoffroy, y Michel Prum (Paris: L’Harmattan. 2012), preface. 
también motricidad e información. Estos conceptos y categorías constituyen lo característico de la articulación entre teología y neurociencias. Es un mapa de categorías reflexivas que evitan el paso directo de un leguaje teológico a uno neurocientífico. En este punto había que hilar fino: no caer en una transposición metafórica, sino acudir a una transgresión de la metáfora (llevar el sentido del lenguaje de la visión neurocientífica a un campo conceptual de la filosofía que sirviera de puente hacia la teología).

El camino consistió en llevar la metáfora del organismo viviente y del conectoma neuronal que se caracterizan por la relacionalidad y la previsión del futuro (la base de la emocionalidad y de la toma de decisiones), hacia la mediación filosófica. Se halló que el término conceptual que permite la articulación podría: ser proyecto o ser para el futuro de la mencionada realidad concreta o ser ahí concreto. Como se ha venido sugiriendo, la relacionalidad, sensibilidad y experiencia suceden en tanto el organismo vivo busca maneras concretas de vivir y proyectarse (anticipación) ${ }^{25}$. Ese ser proyecto mediaba como un término conceptual más amplio que abarcaba las metáforas explicativas del campo de las neurociencias. Así se daba el paso hacia la articulación con la teología. Por su parte, en el campo teológico, la visión de una carne que se relaciona en amistad con la divinidad y que se orienta existencialmente en torno a esa experiencia, se develaba ahora por influjo de la articulación con la visión neurocientífica como una sensibilidad o un vivir realizado como fuente fundamental de una posible vivencia de la divinidad. Fuente en tanto que la divinidad asumió la característica de un darse a la vida humana como proyecto (el humano que opta y realiza a la divinidad como una emoción dada a su sensibilidad, a su proyectualidad y a su capacidad de decisión). En ese giro hacia esa manera de sensibilidad, el vivir concreto del ser humano (carne) se revelaba como la fuente por antonomasia de una posible experiencia de la divinidad.

Pero ¿por qué la estrategia del término ser proyecto o ser para el futuro? Quizás esto quede expuesto con el siguiente asunto: ya se aludió a

25 El ser proyecto (organismo viviente que anticipa) se postula como un término filosófico articulador entre la sensibilidad y experiencia en que consiste la carne en términos teológicos y la movilidad, evolución y anticipación en que se realiza el sistema nervioso. Es un elemento de articulación fundamental que contiene en su definición los dos campos semánticos (teología y neurociencias) y permite el paso de uno hacia otro. 
una carne que dejó de ser experimentada como instrumento de una $\mathrm{Pa}$ labra que le llegaba de Dios, y pasó a ser la carne de Jesús como fuente de esa Palabra. Pues la siguiente pregunta tiene un horizonte parecido: ¿qué ocurrió entre el ser humano que creía que sus pensamientos eran voces divinas, y el ser humano que asume sus pensamientos como suyos propios? Valga recordar que en la historia de la teología ya ha estado presente este problema con lo referente al entendimiento agente: para la tradición platónico-agustiniana, Dios es quien mueve la inteligencia; en cambio para la tradición aristotélico-tomista, el entendimiento agente es una facultad humana. Se podría decir que se trata de dos tipos de conciencias, una que percibe los pensamientos como venidos de otra fuente, y otra que los asocia al "yo". Aún si así fuera, por aporte de las neurociencias cabe preguntar ¿qué tipo de experiencias están en la base de estas configuraciones neuronales? Con esto se reconoce que, más que conciencias, se trata de experiencias, pues por la experiencia se refiguran las conexiones neuronales. La posibilidad de estos tránsitos es que el organismo viviente humano está dado al aprendizaje por ensayo-error y, por lo mismo, por riesgo creativo y vulnerabilidad. Aun así, aceptado lo anterior es pertinente la pregunta por la condición de posibilidad de estas interpretaciones. Es aquí cuando aparece en alto relieve que lo anterior es posible siempre y cuando se trate de un organismo que se da al vivir como proyecto de ser y ser para el futuro, de lo contrario, ni habría ensayo-error, ni re-figuración de las redes neuronales a partir de la experiencia.

\subsection{LA ESPECIFICIDAD INTERNA DE LA TEOLOGÍA COMO ALCANCES}

La carne como rostro concreto del ser ahí y como organismo vivo, realiza la presencia de Dios en el mundo y se convierte en la fuente por preeminencia de la experiencia de Dios. Esto sucede debido a su ser proyecto o ser hacia el futuro pues, como ha ido apareciendo, en este ser proyecto puede ser vivenciada la divinidad a modo de abreviación: el precedente teológico es que Jesús en cuanto organismo viviente y en una vida de un poco más de treinta años, abrevió la divinidad en un vivir realizado en lo cotidiano ${ }^{26}$. No solo es el testimonio teológico de la car-

26 Jesús reconocería en el vaciamiento de Dios, la forma de Dios mismo y optaría por vivir según eso hallado. Tomaría el puesto de Dios: Walter Kasper, Jesús, el 
ne el que dice que hay una relación de amistad entre la carne y Dios y que esta amistad tiende a desarrollarse plenamente en la carne de Jesús; sino también, en una visión neurocientífica evolutiva, toda realización del organismo vivo humano se entroniza a partir del dinamismo de unas emociones que devienen en imágenes y mueven al organismo a actuar en el mundo. Este ser relacional en tanto ser proyecto indica que la posibilidad de una experiencia de Dios pasa por los dinamismos de la materia en evolución. La experiencia de Dios y su Palabra no conforman una realidad dualista frente a los dinamismos de la evolución (quizá las nociones panikkarianas de advaita y realidad cosmoteándrica sirvan de respaldo a este modelo no teísta ni dualista de la experiencia de Dios). Por otra parte, la noción bíblica de kénosis sigue teniendo honda participación en este asunto. El vaciamiento puede implicar dejar que el otro sea en su autonomía y arriesgarse a modo de vulnerabilidad, a realizarse en aquel otro a pesar de la incertidumbre; a pesar de no haber una predisposición inteligente o prediseño que conduzca todo hacia una finalidad prefijada ${ }^{27}$. En todo caso, sería un vaciamiento de la divinidad en los procesos del mundo y sin superposición de planos ni dualidades.

La experiencia de Dios y su Palabra tienen la posibilidad de constituirse a partir de la autonomía del mundo y de entregarse al vaciamiento de sí y a la emergencia de realidades. En el caso de esta articulación, la carne viviente se sitúa como fuente primera y constitutiva de la experiencia de Dios y de la Palabra de Dios. Para entender esto hay que dejar a un lado el modelo teísta de Dios, es decir, no concebir a Dios como una causa eficiente o causa final del mundo, ni como un motor inmóvil, sino como una entrega kenótica. Se arroja a la autonomía del mundo, respeta

Cristo (Salamanca: Sígueme, 1978), 199, 230 y 281. Acerca de la abreviación y recapitulación en la carne de Jesús: Johannes Quasten, Patrología I. Hasta el concilio de Nicea (Madrid: BAC, 1984), 297; la recapitulación es un tema central en san Ireneo de Lyon; la abreviación lo es en Melitón de Sardes y en Orígenes: Jean Daniélou, Mensaje evangélico y cultura helenística, siglos II y III (Madrid: Cristiandad, 2002), 220, 223 y 308 .

27 Kénosis y ciencia: Ian Barbour, La obra del amor, la creación como kénosis (Estella: Verbo divino, 2008); Philip Clayton, Adventures in the Spirit, 63-116; Owen C. Thomas, "Problems in panentheism", en The Oxford Handbook of Religion and science, 657-658; John Polkinghorne, ed., The work of love. Creation as kenosis (Cambridge: SPCK, 2001), 652-664; Olga Consuelo Vélez Caro, "Del Dios omnipotente a la 'humildad de Dios'. Una reflexión sobre la evolución en perspectiva kenótica”, Franciscanum LIV, n. 157 (enero-junio de 2012): 19-50. 
esta autonomía y se somete a su evolución. La carne viviente realiza a Dios en el mundo en cuanto que, en su camino y a modo de homeóstasis, le sale al paso una presencia a la que dota de sentido. La carne viviente puede optar por esta presencia y hallar en ella su plenitud. ¿Pero qué es lo propio de aquello que encuentra?

La carne viviente establece una relación con aquello que la conmociona y seduce en sus dinamismos propios. Esta seducción toma el nombre de testimonio ${ }^{28}$. El testimonio no es en primera instancia una categoría moral ni legal. Es más bien una manera de asumir lo ontológico de la carne. Esto ontológico se puede expresar así: la carne viviente se despliega en la existencia, se constituye como proyecto o ser para el futuro, en búsqueda de sentido (que en el caso humano es más que supervivencia y bienestar). A medida que tiene experiencia y se transfigura por fuerza de ella misma, una palabra o un don se van haciendo relevantes en su devenir existencial. En eso consiste el testimonio: es un darse de algo o alguien bajo algún modo de la experiencia, a una carne viviente para la cual comienza a tener sentido. En el caso estricto de los seguidores de Jesús, aquello que sale al camino como testimonio es la carne de Jesús. Se trata en el evangelio de Juan, de una carne vaciada de sí y dada a los procesos de la cotidianidad, hasta el punto de ofrecerse como vulnerabilidad en la cruz; en el caso de san Pablo, se trata de una carne que comunica un lenguaje loco y necio en cuanto que incluye de nuevo toda vulnerabilidad dentro de la sabiduría de Dios. En estos dos casos se estaría hablando de la kénosis. Aquello que sale al camino de quien se sitúa ante la carne de Jesús, es el testimonio de una carne que se da para generar vida garantizando la autonomía de su realización. Por ello, la carne se presenta como fuente primera, por eminencia, y constitutiva de la teología, dada su situación en el mundo: relacionalidad, sensibilidad y experiencia.

28 El testimonio es una categoría filosófica y teológica: Jean-François Marquet, “Témoignage et Testament", en La Testimonianza, ed., Enrico Castelli (Padova: Casa Editrice Dott. Antonio Milani, 1972), 151-160; Maurice Nédoncelle, "Communication et interprétation du témoignage”, en La testimonianza, 263-290; Germano Pattaro, "Kerigma e Didaké. Continuità e discontinuità della testimonianza", en La Testimonianza, 427-440; Paul Ricoeur, "L’herméneutique du témoignage", en La testimonian$z a, 35-61$; Gianni Vattimo, "Tramonto del soggetto e problema della testimonianza", en La testimonianza, 125-139; Salvador Pié-Ninot, La teología fundamental (Salamanca: Secretariado Trinitario, 2006), 572; Claude Geffré, El cristianismo ante el riesgo de la interpretación. Ensayos de hermenéutica teológica (Madrid: Cristiandad, 1984), 68. 
En el campo del quehacer teológico, ya no se trata de asumir la tradición, el magisterio y la escritura como tres fuentes. Querer hacer de la tradición, el magisterio y la escritura tres fuentes fue el deseo de la teología romana neoescolástica cuando presentó el primer documento para la Constitución Dei Verbum del Concilio Vaticano II. En cambio K. Rahner y lo asumiría la Dei Verbum 9, afirmarían tajantemente que no son tres fuentes sino tres medios de transmisión, tres testimonios de una única fuente que es divina: el Verbo encarnado ${ }^{29}$. El quehacer teológico consistiría en permitir que la carne viviente experimente y hable a Dios. La Escritura ofrece testimonios y es un vehículo para narrar la carne; lo mismo la tradición y el magisterio. Así adquieren su lugar relativo frente a la plenitud que representa la vida y la carne como sensibilidad y experiencia, como proyecto de ser. Recuérdese que Dios mismo es susceptible de ser comprendido como proyecto y de ser abreviado y realizado por la carne viviente como tal. No como un objeto distinto de la carne y de la vida, sino como una realidad relacional. Esto será determinante para comprender la racionalidad epistémica de la teología: no es la búsqueda de principios ontoteológicos, ni de una analogia entis, sino la manifestación y revelación de la divinidad en el qué y cómo de la carne, y esto en el ámbito del vivir.

La carne como fuente indica que Dios no es una causa primera del mundo. Tampoco que es un misterio inaccesible e indecible. Tampoco que es una realidad ajena al mundo y que toca el mundo solo de manera tangencial. Tampoco que es un absoluto trascendente que se mantiene separado mediante un abismo infinito frente a lo inmanente. La carne en tanto fuente fundamental es una invitación a superar estos modos de hablar y de comprender la experiencia de Dios y su Palabra. Superar el modelo teísta y dirigirse hacia un modelo que vincule de parte de la

29 Acerca del conflicto por la fuente de la revelación en el Concilio Vaticano II: Carlos Schickendantz, "Escritura y tradición. Karl Rahner en el 'primer conflicto doctrinal' del Vaticano II", Revista Teología XLVLL, n. ${ }^{\circ} 106$ (diciembre 2011): 347366, 355. El documento de discusión que presentó Rahner se tituló: Disquisitio brevis de schemate "de fontibus revelationis» (noviembre de 1962): es recogido en: Karim Schelkens, \& Brill Academic Publishers, Catholic Theology of revelation on the eve of Vatican II. A redaction history of the schema de Fontibus Revelationis (1960-1962), ed. Will Janse (Boston: Brill, 2010). También: Juan Jesús García Morales, La inspiración bíblica a la luz del principio católico de la tradición. Convergencias entre la Dei Verbum y la teología de P. Benoit, O. P., (Roma: Editrice Pontificia Università Gregoriana, 2012), 42 . 
teología, lo kenótico con el vivir y con la novedad de Jesús; y, de parte de la visión neurocientífica, que vincule la autonomía de la materia en evolución, la aleatoriedad y la anticipación como formas de realización en horizonte de vivir. En ambos casos, la articulación es el ser como proyecto: Dios se vacía de sí para suceder en una amistad con la carne; y Dios es susceptible de realizarse a partir de los dinamismos de un organismo vivo como el humano: es susceptible de ser presencia con sentido en el ámbito de las emociones, de las imágenes mentales y de las decisiones. Es susceptible de la relacionalidad, sensibilidad y experiencia de la vida.

Esto afecta el método del quehacer teológico pues este consistiría en un dejar que el discurso se constituya a partir de la carne como experiencia; permitir que la sensibilidad otorgue lenguajes y categorías nuevas a la teología. Es un discurso que se entroniza a partir de la autonomía del mundo. No es el Dios causa eficiente, ni causa primera, revelándose como luz para que todo ejercicio teológico sea captado bajo esta luz o para que toda realidad mundanal sea captada bajo esta luz; sino que es la carne viviente la que se revela como fuente de la experiencia de Dios y de su Palabra; una carne que es al mismo tiempo, luz y ámbito. La carne se ofrece como luz para el discurso teológico, es decir, se ofrece como un cómo. La carne es el cómo de la revelación. Al mismo tiempo, la carne viviente es lo dado en ella misma o el qué de la revelación que sucede en tanto experiencia. De esta forma, la carne supera la noción de objeto de la teología, pues busca un hablar no objetivante sin fragmentarlo de la vida, y afecta de paso al método. Se deja de crear una escisión entre materialidad y formalidad, para hallar que la carne es en sus propias manifestaciones fontalidad y mediación: qué y cómo de la revelación.

Al tiempo que afecta el método del quehacer teológico, afecta también el objeto-sujeto de la teología. En la carne viviente, Dios no es objeto ni sujeto. Estas categorías quedan superadas pues se entroniza otro modelo: la revelación se realiza en las realidades del mundo y desde la autonomía de la materia: en una epigénesis (génesis comunitaria) con las realidades del mundo. Esto supera el modelo de un Dios perfecto alejado del mundo y lo ubica en el devenir de la vida. En el caso humano, en el devenir de la sensibilidad y de la experiencia. Lo que se puede experimentar y decir de Dios será un lenguaje no objetivante pues ha sucedido en otro modo de comprensión de la vida: sucede en los dinamismos de la carne. 


\subsection{IMPACTOS: GIROS PARA LA ESPECIFICIDAD INTERNA DE LA TEOLOGÍA}

\section{PUNTO DE PARTIDA}

El objeto de la teología era formulado como materialidad y formalidad. Respondía a un qué de la revelación (mundo) y a un cómo de la revelación (luz de la revelación).

\section{OTRA COMPRENSIÓN}

Se hace el giro hacia la sensibilidad (carne). La situación fundamental de la carne hace de ella el qué y el cómo de toda posible comunicación de Dios. Ya no hay un objeto para la teología sino un vivir y hablar no objetivantes.

Se deja de hablar de lugares de teología propios e impropios y se pasa a la comprensión de la teología desde su fuente primera y constitucional: la carne viviente (relacionalidad, sensibilidad, aquello dicho del cerebro-sistema nervioso-organismo viviente).

La tradición, escritura y magisterio se hacen medios de transmisión, pasan a ser testimonia; pero no son fuentes primeras y constitutivas.

30 Para un estudio de los lugares de la teología: Melchor Cano, "De duobus generibus argumentorum, quibus onmis disputatio transigitur", en De Locis Theologicis, Liber primus. Opera In hac primum editione clarius divisa (Patavii: Typis Seminarii, 1734), Cap. II. 1-2; Melchor Cano, "Cómo buscar y extraer los argumentos de teología a partir de los lugares teológicos", en De locis Theologicis (Madrid: BAC, 2006), 776-790; T. Stapleton, Principiorum fidei doctrinalium demonstratio methodica (Parisiis: Apud Michaelem Sonnium, 1579); T. Stapleton, Principiorum fidei doctrinalium relectio scholastica \& compendiaria (Anverpiae: Apud Ioannem Keerbergium, 1506); para la crítica de los lugares de la teología: Yves-Marie Congar, "Le moment 'économique' et le moment 'ontologique' dans la sacra doctrina (révélation, théologie, Somme théologique)", en Mélanges offerts a M.-D. Chenu, Maître en Théologie, Yves-Marie Congar, et al. (Paris: Librairie Philosophique J. Vrin, 1967), 135-188; Karl Rahner, "Teology Today", en Theological Investigations, XXI, Science and Christian faith, Karl Rahner, trad. M. Riley Hugh (New York: Crossroad, 1988), 56-69; Karl Rahner, Escritos de Teología I. Dios-Cristo-María-Gracia (Madrid: Taurus, 1967); Oyente de la Palabra. Fundamentos para una filosofía de la religión (Barcelona: Herder, 1967); Luis Martínez Fernández, Los caminos de la teología. Historia del método teológico (Madrid: BAC, 1997). 


\section{PUNTO DE PARTIDA}

La teología se ha hecho compartimental, se ha especializado llegando cada vez más a ser fragmentaria: fragmentación de la vida y del saber ${ }^{31}$.

\section{OTRA COMPRENSIÓN}

La carne viviente se hace acto hermenéutico fundante de la teología. Ella misma deviene en racionalidad epistémica específica del quehacer teológico y de la posible Palabra de Dios. Rehúsa el deseo de objetivación del lenguaje teológico y busca superar la fragmentación de la vida y del saber teológico ${ }^{32}$.

El método no es la aplicación de reglas, ni está desarticulado de la fuente primera y constitutiva. Es asumido con un volver hacia el vivir (giro de la sensibilidad). En ese vivir, experienciar y ser como proyecto, emerge la Palabra de Dios.

La verificabilidad teológica pasa por el compromiso con el vivir: a) superar la instrumentalización del saber y del vivir; b) la carne es fuente (qué y cómo a gías bíblicas; b) analogías que fueron derivando en una analogia entis, y, a su

Los clásicos criterios de verificación del saber teológico consistían en: a) tipolo-
Unos métodos que tendían a confundir las mediaciones de la teología con la y con la fuente primera. La Palabra de Dios, al buscar ser objetivada, se hacía una entidad de fácil manipulación. 


\section{PUNTO DE PARTIDA}

vez, en una cosificación de la experiencia de Dios; c) la correspondencia entre la estructura del discurso teológico y el magisterio, tradición y escritura; d) la escritura era concebida como un conjunto de disposiciones morales, reglas y contenidos de verdad para argumentar acerca de la verdad.

Se proponía una historia de la salvación con su respectiva economía salvífica. La revelación estaba en función de la salvación. Se exigía un salvador absoluto pues se concebía que toda acción de Dios era dirigida a la libertad (abstracta). Este modelo insistía en la pecaminosidad de la carne.

Por ejemplo, la teología de la liberación continúa con la discusión de si Cristo es objeto formal de las realidades de mundo, o son las realidades del mundo en sí mismas la luz de toda posible revelación. Muestra con ello la urgencia de una reflexión sobre lo específico del quehacer teológico.

\section{OTRA COMPRENSIÓN}

la vez). No requiere una analogía entis; c) magisterio, tradición y escritura son medios de comunicación o testimonios, de una sensibilidad primera (la carne de Jesús); d) la carne viviente opta por realizar en el mundo la divinidad; abrevia y recapitula en la sensibilidad la plenitud de la divinidad. La carne se hace fuente constitutiva no normada.

Se da el paso a una economía de la carne viviente: el punto de partida es el homo vivens (san Ireneo). La clave hermenéutica de la historia no es soteriológica sino kenótica (vaciamiento para otorgar vida). En la lengua materna y cotidiana de Jesús (arameo), no existe la palabra salvación. En cambio, usa vida (hayya a $)^{33}$. Se le resta importancia al pecado y se le concede valor fundamental a la experiencia viva (desprovista de moralina) ${ }^{34}$.

La carne en tanto acto hermenéutico fundamental y fundante (su racionalidad epistémica), hace a un lado los modelos trascendencia-inmanencia, arriba-abajo, cristología desde arriba-cristología desde abajo, causas primeras-causas segundas. Se propone, en cambio, que la sensibilidad (transformación del sistema nervioso, emociones, imágenes mentales, experiencias, decisiones), realiza la divinidad en el mundo.

33 Abdelmumin Aya, El arameo en sus labios. Saborear los cuatro evangelios en la lengua de Jesús (Barcelona: Fragmenta Editorial, 2013), 64.

34 Es curioso que el mismo Nietzsche reconozca que la centralidad de la predicación de Jesús (tipología psicológica) es la vida y la ausencia de toda moralina y exigencias ritualistas: Friedrich Nietzsche, El anticristo, 9 reimpresión (Madrid: Alianza Editorial, 2007), 70-71 §§32 y 33. 


\section{PUNTO DE PARTIDA}

Las teologías de la acción siguen recurriendo a analogados principales y secundarios para expresar la acción de Dios en el mundo (causas eficientes y secundarias), incluso en el diálogo con las neurociencias (Philip Clayton); y también las que dialogan con las mediaciones socioanalíticas (Alberto Parra) ${ }^{35}$.

\section{OTRA COMPRENSIÓN}

La racionalidad epistémica de la carne sitúa la revelación en una epigénesis con el mundo. Se valora la sensibilidad y las realidades del mundo en cuanto tales. En este horizonte mundanal es donde se abrevia, capitula y realiza la posibilidad de la divinidad. No hace falta recurrir a modelos teístas.

\subsection{NovedAdES y APORTES DE LA INVESTIGACIÓN A LA TEOLOGÍA}

Se podría decir, en general, que son tres novedades principales de la tesis: a) la sistematización de recursos teológicos y bíblicos que permitieron que la carne se manifestara como la radical fuente primera (preeminencia), y constitutiva de la teología. Quizás algunas teologías asuman la carne de manera parecida; pero la manera en que aquí se formula no había estado propuesta como tal. La tesis queda enunciada así: el trato articulador entre el testimonio teológico de la carne y una visión neurocientífica evolutiva, estructura de otra manera (desde otra epistemología y otro giro hermenéutico), la especificidad interna de la teología. Esta otra manera es la carne como fuente primera y constitutiva de la teología; una carne que abrevia la divinidad y la realiza en los dinamismos propios del mundo y de la materia en evolución, en su autonomía, y debido a la sensibilidad y la experiencia. Sensibilidad y experiencia tienen la fuerza de hacer presente a Dios en el mundo y de ser fontalidad de la Palabra de Dios; b) otra novedad es la articulación entre teología y neurociencias en la perspectiva del ser proyecto, ser para el futuro, relacionalidad, sensibilidad y experiencia; c) apostar por dirigir la reflexión hacia la especificidad

35 Ph. Clayton propone que la realidad es una sucesión de capas y niveles ontológicos que admiten, en cada ámbito, diversas formas de causalidades. En alguna de ellas se admite la causalidad eficiente de Dios en el mundo. Según él, esto no contradice la ciencia empírica: Vicente Valenzuela Osorio, "Enfoques y postura crítica de la relación entre teología y neurociencias", Theologica Xaveriana 68, n. ${ }^{\circ} 185$ (enero-junio 2018): 1-27, 10-15. También Alberto Parra insiste en la necesidad de una causa eficiente de la acción de Dios: Alberto Parra, "De camino a la teología de la acción", Theologica Xaveriana 63, n. 175 (enero-junio 2013): 143-171. 
interna de la teología. Esto es importante ya que, en cada rastreo hecho a los discursos que han reflexionado la teología y las neurociencias, se notó que ninguno trabajó la cuestión fundamental y específica de la teología. Hay trabajos que reflexionan y defienden la causalidad divina y el cerebro (divine action) como los de Ph. Clayton; que yuxtaponen antropologías como los de A. Ganoczy; que se interesan por la religión y las facultades del cerebro para la espiritualidad como la neuroreligión y la neuroteología; o, que se interesan por el asunto ético-moral y el cerebro, como se publicó una edición de la revista Concilium. Pero en ningún caso se dio trato a la cuestión interna de la teología ni a su epistemología a partir de una articulación entre teología y neurociencias ${ }^{36}$.

36 La situación del influjo de la neurociencia en algunos centros formativos en Europa y sus deficiencias: Bartosz Brozek, y Michael Heller, "Science and religion in the Kraków School” Zygon 50, n. 1 (March 2015): 194-208 (denuncia el escolasticismo que instrumentaliza la ciencia); James McMahon, "Aspects of self-Consciousness and predicted religious identification change in Romania -Roles for Psychology and Theology-", Transylvanian Journal of Psychology n. ${ }^{\circ} 2$ (2015): 111-122 (propone una visión axiológica del progreso de la ciencia para Rumania); Lluís Oviedo, y Álvaro Garre, "The interaction between religion and science in Catholic southern Europe", 172-193 (la teología europea sigue sin incorporar la ciencia moderna); Charlene P. E. Burns, "Christianity and the cognitive sciences", 308-319 (escrito de neuroteología, Propone que la relación con Dios es el alma); Philip Clayton, y Zachary Simpson, eds., The Oxford Handbook of Religion and science (Colección de artículos sobre la relación ciencia y religión. Algunos tratan de neuroteología, otros, de los planteamientos de Clayton); b) textos donde se vincula las neurociencias con un elemento regional (no constitutivo) de la teología: Kirk A Bingaman, "Beyond Original Sin", 411-422, (propone que se evite seguir hablando de pecado pues es nocivo para la salud cerebral); Alan C. Weissenbacher, "The neuroscience of Wesleyan soteriology: The dynamic of both instantaneous and gradual change", Zygon 51, n. 2 (June 2016): 347-360 (es una apología a la acción directa de la gracia de Dios en el cerebro); Carol Rausch Albright, "James B. Ashbrook and his holistic world", 479-489 (es una síntesis integracionista (no articuladora) de mundo-cerebro-Dios); c) investigaciones que vinculan experiencias místicas, alucinógenas y neurociencias: Ron Cole-Turner, "Entheogens, mysticism, and neuroscience", 642-651 (apología a la diferencia entre experiencia religiosa alucinógena y experiencia mística tradicional); Leonard Hummel, "By its fruits?", 685-695 (revisa la pertinencia de incorporar alucinógenos como ayuda terapéutica en rituales y comunidades cristianas); David E. Nichols, y Benjamin R. Chemel, "The Neuropharmacology of Religious Experience: Hallucinogens and the Experience of the Divine", en Where God and Science meet. How Brain and Evolutionary Studies Alter Our Understanding of Religion, vol. 3, The pshycology of Religion Experience, ed., Patrick McNamara (Westport, CT: Praeger Publishers, 2006), 1-33 (trata sobre alucinógenos y experiencia religiosa); d) también los ya citados trabajos de yuxtaposición de antropologías bíblicas y de las neurociencias en Ganoczy, y de la divine action en Ph. Clayton: Vicente Valenzuela Osorio, “Enfoques y postura crítica”, 10-15. 


\section{CONCLUSIONES}

a. La clave metódica que permite mantener el discurso en una cohesión e interés específico es el organismo viviente. No se tomó al sujeto ni la subjetividad, sino que se buscó pensar el asunto a partir del organismo dado al vivir. Junto a esto se propuso que la clave hermenéutica es la carne como acto hermenéutico fundamental y rostro concreto del ser ahí. De este modo, se buscaba recuperar la primacía de la carne frente a la experiencia y Palabra de Dios.

b. Los dinamismos del organismo vivo humano motricidad, sensibilidad y experiencia (sucedidos en el conectoma neuronal), son susceptibles de ser alcanzados por el modo ontológico de testimonio. La vida humana puede vivirse como proyecto de ser, y en este proyecto abreviar y realizar la divinidad (en la teología patrística, la carne de Jesús abrevia la divinidad en cuanto que la divinidad es revelada en una vida con sus respectivas experiencias). En este caso, el testimonio del ser de Dios o ser kenótico puede darse al ámbito de las emociones y ser recibido como decisión sobre el mundo. Esto es una superación de la idea de un Dios absoluto, todopoderoso y perfecto, para dar el paso a la comprensión de un Dios que consiste en ser la gloria del humano viviente, pero a condición de reconocerle la capacidad que el vivir tiene realizar a Dios en la propia experiencia. Las clásicas perfecciones de Dios y los trascendentales del ser de la teología medieval se ven replanteados por un giro hacia la sensibilidad de la carne viviente. Esto es determinante no solo en el modo de comprender los modelos de Dios, sino también, en cuanto a los clásicos lugares de la teología.

c. Los lugares de la teología ya no pretenderían hallar lo bueno, perfecto y verdadero, ni lo santo y sagrado de las realidades mundanales, sino que: a) se sabrían deudores de la carne como fuente primera y constitutiva; y b) interactuarían con las sensibilidades y experiencias sin pretender códigos de pureza ni de santidad en las mismas. No se accedería a la sensibilidad ni a la experiencia por que sean buenas o malas, ni por su relación o no con la Biblia, sino en cuanto ellas (sensibilidad y experiencia) son susceptibles del darse de un testimonio a la existencia humana; susceptibles de una entrega de la vida para que otros y otras la tengan en abundancia. Este interés no lo definen las categorías morales, sino la comprensión de la carne a la luz de cuanto sucede en la carne misma. 
d. Reconocido que toda experiencia y sensibilidad es asumida como tal y no por causas morales o de santidad, se propone que el quehacer teológico es eminentemente respetuoso de los modos de ser, de las maneras de la vida. Pero que la condición de verificabilidad de la carne como revelación es el darse del testimonio en el existir humano. Aquel testimonio que en la carne de Jesús consiste en descubrir que el ser del Abbá es despojarse de sí mismo y asumir como opción personal ese testimonio encontrado. La carne ante la carne de Jesús toma el lugar de Dios para realizarlo y abreviarlo como presencia (la carne como sensibilidad tiene la posibilidad de abreviar en el transcurso de una vida, de una existencia o de un instante, la divinidad); una presencia que sucede en los dinamismos de la vida. Esta carne ante la carne de Jesús se transforma mediante la experiencia en que consiste aquella carne. La transformación sucede en todo el organismo viviente en cuanto este es un proyecto de ser. Incluye la creatividad en las emociones (o la creatividad en las relaciones con el mundo), la refiguración de las imágenes mentales y pensamientos; y la transformación de la realidad.

e. Cabe decir que este modo de asumir lo específico de la teología ha afectado la clave de comprensión de ella misma y su estatuto epistemológico. No solo cambia el método y critica la idea de objeto, sino que también dice que la epistemología específica de la teología es la carne como sensibilidad y experiencia capaz de abreviar la divinidad en el vivir (hacer del instante, de la experiencia y de la sensibilidad, la vivencia plena de la divinidad), a la vez que ser fuente de la experiencia y Palabra de Dios. Por ello mismo es una epistemología abierta a la creatividad y al devenir. No es temerosa de hallar la divinidad bajo diversos testimonios, ni de hallar a Jesús en la pluralidad de respuestas que implica la kénosis. En Latinoamérica, posicionar la carne como fuente primera y constitutiva de la teología es reconocer la posibilidad de que las realidades del mundo, en su autonomía, pueden expresar a Dios y su Palabra. Hacer el camino de la articulación con las neurociencias ha permitido enriquecer la visión sobre esta autonomía y hallar que entre teología y ciencia puede haber un diálogo reflexivo-articulador que no descuide la realidad de los seres humanos y demás vivientes. Es una invitación a cultivar todo tipo de sensibilidad en toda forma de vida; y a hallar toda manera de experiencia como fundante de la divinidad. 


\section{REFERENCIAS}

"Cómo se conectan las neuronas". Redes para la ciencia. Emisión 160 del 16 de junio de 2013. Temporada 17. Consultado el 03 de marzo de 2017. http://www.redesparalaciencia.com/wp-content/uploads/ 2013/06/entrev1601.pdf

"Interlinear Bible". Bible Hub. 2004-2017. consultado 08 de diciembre de 2018. http://biblehub.com/interlinear/

Alonso Schökel, L. Hermenéutica de la Palabra. I hermenéutica bíblica. Madrid: Cristiandad, 1986.

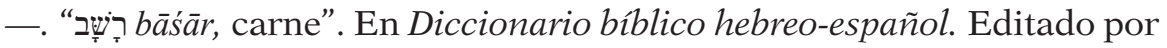
Víctor Morla y Vicente Collado, 139-140. Madrid: Trotta, 1994.

Aya, Abdelmumin. El arameo en sus labios. Saborear los cuatro evangelios en la lengua de Jesús. Barcelona: Fragmenta Editorial, 2013.

Balthasar, Hans Urs von. Teodramática I. Madrid: Encuentro, 1990.

—. Gloria. Una estética teológica, 7. Madrid: Encuentro, 1989.

Barbaglio, Giuseppe. Jesús de Nazaret y Pablo de Tarso. Confrontación histórica. Salamanca: Secretariado trinitario, 2009.

Barbour, Ian. La obra del amor, la creación como kénosis. Estella: Verbo divino, 2008.

Beinert, Wolfgang. Die Leib-Seele-Problematik in der Theologie. Regensburg: Karl Rahner Akademie, 2002.

Bingaman, Kirk A. "Beyond Original Sin: A Paradigm Shift for the Age of Neuroscience". Pastoral Psychology, 61 (2012): 411-422. https://doi. org/10.1007/s11089-012-0432-5

Blanco, Carlos. Historia de la neurociencia. El conocimiento del cerebro y la mente desde una perspectiva interdisciplinar. Madrid: Siglo XXI, 2014.

Bourgine, Benoît, Bernard Feltz, Pierre-Joseph Laurent, y Ph van den Bosch de Aguilar, dirs. Darwinismes et spécificité de l'humain. Louvain-la-Neuve: Editions Academia, 2012.

Bratsiotis, N. P. "“רָ bāsāâr". En Theological dictionary of the Old Testament II. Editado por G. Johannes Botterweck, Heinz-Josef Fabry, y Helmer Ringgren; traducido por John T. Willis, 317-332. Michigan: Eerdmans, 1983.

Brown, Raymond E. La comunidad del discípulo amado. Estudio de la eclesiología juánica. Salamanca: Sígueme, 2005.

—. El evangelio según Juan I-XII. Madrid: Cristiandad, 1999.

Brueggemann, Walter. Teología del Antiguo Testamento. Un juicio a Yahvé. Salamanca: Sígueme, 2007. 
Burns, Charlene P. E. "Christianity and the cognitive sciences". En The Routledge Companion to Religion and Science. Editado por James W. Haag, Gregory R. Peterson, y Michael L. Spezio, 308-319. New York: Routledge, 2014.

Cáceres Vázquez, Emilio. Creacionismo y diseño inteligente frente a evolución. Un debate inexistente. Madrid: Hélice, 2011.

Cano, Melchor. "De duobus generibus argumentorum, quibus onmis disputatio transigitur". En De Locis Theologicis, Liber primus. Opera In hac primum editione clarius divisa, 1-2. Patavii: Typis Seminarii, 1734.

- . "Cómo buscar y extraer los argumentos de teología a partir de los lugares teológicos”. En De locis Theologicis, 776-790. Madrid: BAC, 2006.

Castro García, Óscar. "La biosemiótica y la biología cognitiva en organismos sin sistema nervioso". Ludus vitalis XIX, n. 36 (2011): 47-84.

Clayton, Philip. Adventures in the Spirit. God, World, divine Action. Minneapolis MN: Fortress Press, 2008.

Clayton, Philip, y Arthur Peacocke, eds. In whom we live and move and have our being. Panentheistic Reflections on God's Presence in a Scientific World. Cambridge: Eerdmans, 2004.

Cole-Turner, Ron. "Entheogens, mysticism, and neuroscience". Zygon 49, n. ${ }^{\circ} 3$ (September 2014): 642-651.

Congar, Yves-Marie. 'Le moment 'économique' et le moment 'ontologique' dans la sacra doctrina (révélation, théologie, Somme théologique)". En Mélanges offerts a M.-D. Chenu, Maître en Théologie, en Yves-Marie Congar, et al., 135-188. Paris: Librairie Philosophique J. Vrin, 1967.

Craig S., Keener. "Commentary on 1 Corinthians". En 1-2 Corinthians, 20-139. New York: Cambridge Press, 2005.

Damásio, Antonio. El error de Descartes. La razón de las emociones. Santiago de Chile: Andrés Bello, 1996.

-. Sentir lo que ocurre. Cuerpo y emoción en la fábrica de la conciencia. Santiago, Chile: Salesianos S. A., 2000.

-. Y el cerebro creó al hombre. ¿Cómo pudo el cerebro generar emociones, sentimientos, ideas y el yo? Barcelona: Destino, 2010.

Daniélou, Jean. Mensaje evangélico y cultura helenística, siglos II y III. Madrid: Cristiandad, 2002.

Darwin, Charles. El origen de las especies por medio de la selección natural. Tomo I. Madrid-Buenos Aires: Espasa-Calpe, 1921. https://doi. org/10.5962/bhl.title.70891

- The descent of man, and selection in relation to sex. Princeton: Princeton University Press, 1981. 
De Wit, Hans. En la dispersión el texto es patria. Introducción a la hermenéutica clásica, moderna y postmoderna. San José Costa Rica: Universidad Bíblica Latinoamericana, 2002.

Echarte, Luis E. "Proyección y límites de la neuroteología en el pensamiento de Aldous Huxley. La interdisciplinariedad a prueba en estudios existenciales". Persona y bioética 13, n. ${ }^{\circ} 1$ (2009): 42-58.

Edelman, Gerald M. Biologie de la conscience. Paris: Éd. Odile Jacob, 1994.

Eichrodt, Walter. Teología del Antiguo Testamento I. Madrid: Cristiandad, 1975.

Falque, Emmanuel. Dios, la carne y el otro. De Ireneo a Duns Scoto: reflexiones fenomenológicas. Bogotá: Siglo del Hombre editores, 2012.

Ganoczy, Alexandre. Cristianisme et neurosciences. Pour une théologie de l'animal humain. Paris: Odile Jacob, 2008.

García Morales, Juan Jesús. La inspiración bíblica a la luz del principio católico de la tradición. Convergencias entre la Dei Verbum y la teología de P. Benoit, O. P. Roma: Editrice Pontificia Università Gregoriana, 2012.

Geffré, Claude. El cristianismo ante el riesgo de la interpretación. Ensayos de hermenéutica teológica. Madrid: Cristiandad, 1984.

Gesché, Adolphe. "L'invention chrétienne du corps". En Le corps chemin de Dieu. Editado por Aldolphe Gesché y Paul Scolas, 33-75. Paris: Les éditions du Cerf; Université Catholique de Louvain, 2005.

Geschwind, Norman. "Especializaciones del cerebro humano". Investigación y ciencia, El lenguaje humano 5 (1996): 8-19.

Gregersen, Niels Henrik. "Emergency and Complexity". En The Oxford Handbook of Religion and Science. Editado por Philip Clayton, 767783. Oxford: Oxford University Press, 2008.

Haught, John F. God after Darwin. A theology of evolution. Philadelphia: Westview Press, 2008.

Heidegger, Martin. "Fenomenología y teología”. En Hitos, versión de Helena Cortés y Arturo Leyte, 45-78. Madrid: Alianza Editorial, 2000.

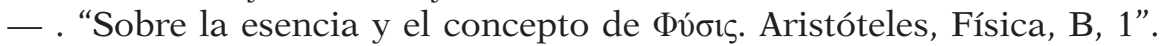
En Hitos, versión de Helena Cortés y Arturo Leyte, 129-249. Madrid: Alianza Editorial, 2000.

- De la esencia de la verdad. Sobre la parábola de la caverna y el Teeteto de Platón. Madrid: Herder, 2007.

—. Escritos de Teología I. Dios-Cristo-María-Gracia. Madrid: Taurus, 1967.

-. Identidad y diferencia. Barcelona: Anthropos, 1988.

Heller, Michael, y Bartosz Brozek. "Science and religion in the Kraków School”. Zygon 50, n. 1 (March 2015): 194-208. 
Henri, Michel. Encarnación. Una filosofía de la carne. Salamanca: Sígueme, 2001.

Hummel, Leonard. "By its fruits? Mystical and visionary states of consciousness occasioned by entheogens". Zygon 49, n. 3 (noviembre 2014): 685-695.

Ireneo de Lyon. Libros quienque adversus haereses. Textu gaeco in locis nonnullis locupletato, versione latina cum codicibus claromontano ac arundeliano denuto collata. Tom. II. Collegii, W. Wigan Harvey, STB. Cantabrigiae: Typis Academicis, 1857.

- Demostración de la predicación apostólica. Fuentes patrísticas 2. Traducido por Eugenio Romero Pose. Madrid: Ciudad Nueva, 1992.

Jasper, Herbert H., et. al., "Neuroscience". En History of the American physiological society. The first century. Editado por John R. Brobeck, Orr E. Reynolds, y Toby A. Appel, 427-434. New York: Library of Congress, 1987.

Jiménez-Rodríguez, Luis Orlando. The articulation between natural sciences and systematic theology. A philosophical mediation based on the contributions of Jean Ladrière and Xavier Zubiri. Leuven-Paris-Bristol: Ed. Ephemerides theologicae lovanienses, 2015.

- . "It is reasonable to upload a non-reductive Christian monism? Theology confronted with the mind-brain and body-soul problem". Pensamiento 71, n. 269 (2015): 1323-1345.

-. "Une articulation des sciences et de la théologie est-elle légitime?". Nouvelle revue théologique 119 (1997): 520-540.

Kasper, Walter. Jesús, el Cristo. Salamanca: Sígueme, 1978.

Ladrière, Jean. L'articulation de sens I. Discours scientifique et parole de la foi. Paris: Cerf, 1970.

-. L'articulation de sens II. Les langages de la foi. Paris: Cerf, 1984.

-. L'articulation de sens III. Sens et vérité en théologie. Paris: Cerf, 2004.

—. "Science et théologie". Revue Théologique de Louvain 34 (2003): 3-26. https://doi.org/10.2143/RTL.34.1.2017473

Lambert, Dominique. Sciences et théologie. Les figures d'un dialogue. Namur: Lessius, 1999.

Llinás, Rodolfo R. El cerebro y el mito del yo. El papel de las neuronas en el pensamiento y el comportamiento humanos. Bogotá: Ed. Normal, 2003.

Loza Vera, José, y Raúl Duarte Castillo. Introducción al Pentateuco, Génesis. Biblioteca bíblica básica 3. Estella: Verbo Divino, 2007.

Marquet, Jean-François. "Témoignage et Testament”. En La Testimonianza. Editado por Enrico Castelli, 151-160. Padova: Casa Editrice Dott. Antonio Milani, 1972. 
Martínez Fernández, Luis. Los caminos de la teología. Historia del método teológico. Madrid: BAC, 1997.

Martínez Morales, Víctor. "Aproximación a las racionalidades especializadas y sus métodos en el quehacer teológico". En Los métodos en teología, Gustavo Baena Bustamante, Darío Ernesto Martínez Morales, Víctor Marciano Martínez Morales, José Alfredo Noratto Gutiérrez, y Gabriel Alfonso Suárez Medina; Pontificia Universidad Javeriana. Facultad de Teología. Equipo Interdisciplinario de Docencia e Investigación Teológica, 39-52. Bogotá: Ed. Pontificia Universidad Javeriana, 2007.

Mateos, Juan, y Juan Barreto. El evangelio de Juan. Análisis lingüístico y comentario exegético. Madrid: Cristiandad, 1992.

Maturana, Humberto. La objetividad, un argumento para obligar. Santiago de Chile: Dolmen, 1997. https://doi.org/10.1007/978-94-009-8947-4

Maturana, Humberto, y Francisco J. Varela. Autopoiesis and Cognition. The realization of the living. London: Reidel Publishing Company, 1980.

McMahon, James. "Aspects of self-Consciousness and predicted religious identification change in Romania - Roles for Psychology and Theology". Transylvanian Journal of Psychology n. 2 (2015): 111-122.

Moltmann, Jürgen. El Dios crucificado. La cruz de Cristo como base y crítica de toda teología cristiana. Salamanca: Sígueme, 2010.

-. "Resurrección y futuro de Jesucristo". En Teología de la esperanza, 181-298. Salamanca: Sígueme, 1969.

Nédoncelle, Maurice. "Communication et interprétation du témoignage”. En La Testimonianza, editado por Enrico Castelli, 263-290. Padova: Casa Editrice Dott. Antonio Milani, 1972.

Nichols, David E., y Benjamin R. Chemel. "The Neuropharmacology of Religious Experience: Hallucinogens and the Experience of the Divine". En Where God and Science meet. How Brain and Evolutionary Studies Alter Our Understanding of Religion. Vol. 3, The pshycology of Religion Experience, editado por Patrick McNamara. 1-33. Westport, CT: Praeger Publishers, 2006.

Nietzsche, Friedrich. El anticristo. $9^{\text {a }}$ reimpresión. Madrid: Alianza Editorial, 2007.

Nogués, Ramón María. Dioses, creencias y neuronas. Una aproximación científica a la religión. Barcelona: Fragmenta editorial, 2011.

Orbe, Antonio. Teología de san Ireneo IV. Traducción y comentario del libro IV del Adversus Haereses. Madrid: BAC maior, 1996.

Oviedo, Lluís, y Álvaro Garre. "The interaction between religion and science in Catholic southern Europe (Italy, Spain, Portugal)". Zygon 50, n. ${ }^{\circ} 1$ (March 2015): 172-193. 
Panikkar, Raimon. La puerta estrecha del conocimiento. Sentidos, razón y fe. Barcelona. Herder, 2009.

-. Ontonomía de la ciencia. Sobre el sentido de la ciencia y sus relaciones con la filosofía. Madrid: Gredos, 1961.

—. La nueva inocencia. Estella: Verbo Divino, 1999.

—. La plenitud del hombre. Una cristofanía. Madrid: Siruela, 1999.

Parra, Alberto. Textos, contextos y pretextos. Teología fundamental. Colección Teología hoy N. ${ }^{\circ}$ 44. Bogotá: Pontificia Universidad Javeriana, 2003.

Parra, Alberto. "De camino a la teología de la acción". Theologica Xaveriana 63, $\mathrm{n}^{\circ} .175$ (enero-junio 2013): 143-171.

Pattaro, Germano. "Kerigma e Didaké. Continuità e discontinuità della testimonianza". En La Testimonianza, editado por Enrico Castelli, 427-440. Padova: Casa Editrice Dott. Antonio Milani, 1972.

Pérez Prieto, Victorino. Más allá de la fragmentación de la teología. El saber y la vida: Raimon Panikkar. Valencia: Tirant lo Blanch, 2008.

-. Dios, hombre, mundo. La Trinidad en Raimon Panikkar. Barcelona: Herder, 2008.

Pié-Ninot, Salvador. La teología fundamental. Salamanca: Secretariado Trinitario, 2006.

Polkinghorne, John, ed. The work of love. Creation as kenosis. Cambridge: SPCK, 2001.

-. Ciencia y teología. Una introducción. Santander: Sal Terrae, 2000.

Quasten, Johannes. Patrología I. Hasta el concilio de Nicea. Madrid: BAC, 1984.

Rad, Gerhard von. Teología del Antiguo Testamento I. Las tradiciones históricas de Israel. Editado por Luis Alonso Schökel. Salamanca: Sígueme, 1993.

Rahner, Karl. "Teology Today". En Theological Investigations, XXI, Science and Christian faith. Traducido por M. Riley Hugh, 56-69. New York: Crossroad, 1988.

-. Oyente de la Palabra. Fundamentos para una filosofía de la religión. Barcelona: Herder, 1967.

Rahner, Karl, Jürgen Moltmann, Christian Duquoc, Stanislas Breton, Abelardo Lobato, Ignace de La Potterie, Domenico Grasso, Walter Kasper, Hans Küng. Teología de la Cruz. Salamanca: Sígueme, 1979.

Rahner, Karl, y Wilhem Thüsing. Cristología: estudio teológico y exegético. Madrid: Cristiandad, 1975.

Ramón y Cajal, Santiago. Histología del sistema nervioso del hombre y de los vertebrados. Tomo I. Madrid: Ministerio de Sanidad y consumo; Consejo superior de investigaciones científicas, 2007. 
Rausch Albright, Carol. "James B. Ashbrook and his holistic world: Toward a 'unified field theory' of mind, brain, self, world, and God". Zygon 45, n. ${ }^{\circ} 2$ (June 2010): 479-489.

Ricoeur, Paul. "L'herméneutique du témoignage". En La Testimonianza, editado por Enrico Castelli, 35-61. Padova: Casa Editrice Dott. Antonio Milani, 1972.

Robinson, Maurice A. Pierpont, William G. The New Testament in the Original Greek: Byzantine Text form. Chilton Book Publishing, 2005.

Ruiz de la Peña, Juan Luis. Imagen de Dios. Antropología teológica fundamental. Santander: Sal Terrae, 1988.

Sarasa Gallego, Luis Guillermo. La filiación de los creyentes en el Evangelio de Juan. Bogotá: Edición Facultad de Teología, Pontificia Universidad Javeriana, 2010.

-. "El prólogo de Juan, un principio y fundamento". Cuestiones teológicas 39, n. ${ }^{\circ} 91$ (enero-junio, 2012): 99-117.

Schelkens, Karim, \& Brill Academic Publishers. Catholic Theology of revelation on the eve of Vatican II. A redaction history of the schema de Fontibus Revelationis (1960-1962). Editado por Will Janse. Boston: Brill, 2010.

Schickendantz, Carlos. "Escritura y tradición. Karl Rahner en el 'primer conflicto doctrinal' del Vaticano II". Revista Teología XLVLL, n. ${ }^{\circ} 106$ (diciembre 2011): 347-366.

Schweizer, E. "B. Carne nell' A. T.”. En Grande Lessico del Nouvo Testamento XI, dirigido por Gerhard Kittel. Editado por Gerhard Friedrich. Traducido al italiano por F. Montagnini, G. Scarpat, y O. Soffritti, 1290-1294. Brescia: Paideia, 1977.

Sesboüé, Bernard. Tout récapituler dans le Christ. Christologie et sotériologie d'Irénée de Lyon. Paris: Desclée, 2000.

Sicre, José L. Los profetas de Israel y su mensaje. Antología de textos. Madrid: Cristiandad, 1986.

Söding, Thomas. "Encarnación y pascua, la historia de Jesús tal como se refleja en el Evangelio de Juan". Selecciones de teología 42, n. ${ }^{\circ} 172$ (oct-dic 2004): 305-312.

Stapleton, T. Principiorum fidei doctrinalium demonstratio methodica. Parisiis: Apud Michaelem Sonnium, 1579.

-. Principiorum fidei doctrinalium relectio scholastica \& compendiaria. Anverpiae: Apud Ioannem Keerbergium, 1506.

Támez, Elsa. "La carta de Pablo a los Filipenses desde la perspectiva de un prisionero político". Revista bíblica 3, n. 4 (2012): 193-217. 
Thomas, Owen C. "Problems in panentheism". En The Oxford Handbook of Religion and Science, editado por Philip Clayton, 657-658. Oxford: Oxford University Press, 2008.

Tort, Patrick. "Ce qui a changé (dans) les études darwiniennes". En Darwin dans la bataille des idées, dirigido por Sophie Geoffroy, Michel Prum, Preface. Paris: L'Harmattan, 2012.

Udías Vallina, Agustín. Conflicto y diálogo entre ciencia y religión. Santander: Sal Terrae, 1993.

Valenzuela Osorio, Vicente. "Enfoques y postura crítica de la relación entre teología y neurociencias". Theologica Xaveriana 68, n. ${ }^{\circ} 185$ (enero-junio 2018): 1-27.

Valenzuela Osorio, Vicente. "La carne vulnerable como fuente primera y constitutiva de la teología. Articulación del testimonio teológico de la carne con una visión neurocientífica evolutiva". Doctorado en teología, Pontificia Universidad Javeriana, Bogotá, 2017.

Varela, Francisco. El fenómeno de la vida. Santiago de Chile: Dolmen, 2002.

Vattimo, Gianni. "Tramonto del soggetto e problema della testimonianza". En La Testimonianza, editado por Enrico Castelli, 125-139. Padova: Casa Editrice Dott. Antonio Milani, 1972.

Vélez Caro, Olga Consuelo. "Del Dios omnipotente a la 'humildad de Dios'. Una reflexión sobre la evolución en perspectiva kenótica”. Franciscanum LIV, n. ${ }^{\circ} 157$ (enero-junio de 2012): 19-50.

Vidal, Senén. "Filipenses". En Las cartas auténticas de Pablo, 529-568. Bilbao: Mensajero, 2012.

-. El proyecto mesiánico de Pablo. Salamanca: Sígueme, 2005.

—. Las cartas originales de Pablo. Madrid: Trotta, 1996.

Weissenbacher, Alan C. "The neuroscience of Wesleyan soteriology: The dynamic of both instantaneous and gradual change". Zygon 51, n. ${ }^{\circ} 2$ (June 2016): 347-360.

Wengst, Klaus. "Il prologo (1, 1-18)". En Il Vangelo di Giovanni, 31-77. Brescia: Queriniana, 2005.

Wikenhauser, Alfred. "Prólogo 1, 1-18". En El Evangelio según san Juan, 61-68. Barcelona: Herder, 1972.

Wolff, Hans Walter. Antropología del Antiguo Testamento. Salamanca: Sígueme, 1975.

Zañartu, Sergio. "La salvación de la carne según Ireneo en Adv. Haer. V, 1-14. Breve presentación de conjunto. 'Fructus autem operis spiritus est carnalis salus' (V, 12, 4, 77s)”. Teología y vida 54 (2013): 43-78.

Zubiri, Xavier. Sobre el hombre. Madrid: Alianza Editorial, 1986. 